\title{
Enhancement of rhizocompetence in pathogenic bacteria removal of constructed wetland system
}

\author{
Marwa BEN SAAD ${ }^{1}$, Myriam BEN SAID ${ }^{1}$, Isabel SANZ SÁEZ ${ }^{2}$, Olga SANCHEZ ${ }^{3}$, Jordi \\ MORATO $^{4}$, Latifa BOUSSELMI ${ }^{1}$ and Ahmed GHRABI ${ }^{1}$ \\ ${ }^{1}$ Water Researches and Technologies Center, CERTE, BP 273 - 8020 Soliman Tunisia \\ ${ }^{2}$ Institut de Ciències del Mar (ICM-CSIC), Pg. Marítim de la Barceloneta,08003 Barcelona, Spain \\ ${ }^{3}$ Department of Genetics and Microbiology Faculty of Biosciences, UAB 08193 Bellaterra Barcelona Spain \\ ${ }^{4}$ UNESCO Chair in Sustainability, Polytechnic University of Catalunya, C1 Terrassa, 08222, Barcelona, Spain \\ "marwabensaad@gmail.com
}

\section{Abstract}

The main goal of the present study was to enhance the rhizobacterium potential in horizontal subsurface flow constructed wetland system planted by Phragmites australis through environmentally friendly biological approaches. The bioinoculation of antagonist bacteria has been used to promote higher rhizosphere competence in pathogenic bacteria removal. The experience was performed with once and with sequential bio-inoculation. The results show that the strain $\mathrm{PFH}_{1}$ played an active role in pathogenic bacteria removal. In fact, the individual bioinoculated improves remarkably the inactivation kinetics of a pathogenic tested bacteria; S. typhi in plant rizosphere by, $0.8 \mathrm{U}-\log _{10}$ with once bio-injection and approximately, $2.5 \mathrm{U}-\log _{10}$ with sequential bio-injections. These results suggested that this strain represents a promising candidate to improve the water purification by constructed wetland.

Key words: Antagonism, Bioinoculation, Constructed Wetland, Rhizosphere.

\section{Introduction}

Constructed wetlands (CWs) have been used as a green technology to treat various wastewaters for several decades. They offer a land-intensive, low-energy, and less operational-requirements alternative to conventional treatment systems, especially for small communities and remote locations(Ghrabi et al. 2011; Shen et al. 2015; Tee et al. 2016) (Ghrabi et al. 2011; S. Wu et al. 2015) These engineered systems are designed to treat contaminants in surface water, groundwater or waste streams by using natural functions of 
1 wetland vegetation, soils and their microbial populations (Vymazal 2014). They have a great

2 potential for the treatment of wastewater of different origin (Wang et al. 2015; Zaytsev et al.

3 2011) such as domestic sewage, agricultural wastewater, industrial effluent, mine drainage,

4 landfill leachate, urban runoff, and polluted river water (Liu et al. 2015). CWs have been

5 successfully used to mitigate environmental pollution by removing of a wide variety of

6 pollutants from wastewater such as organic compounds, suspended solids, pathogens, metals,

7 and nutrients (Zhang et al. 2014). During wastewater treatment in CWs, pollutants are

8 removed through an integrated combination of biological, physical and chemical interactions

9 between the plants, the substrate and the inherent microbial community (Wang et al. 2015).

10 CWs are typically classified into two types according to the wetland hydrology: free water 11 surface (FWS) CWs and subsurface flow (SSF) CWs. FWS systems are similar to natural wetlands, with a shallow flow of wastewater over a saturated substrate. On SSF systems, wastewater flows through the substrate which supports the growth of plants, and based on the flow direction, SSF CWs could be further divided into vertical flow (VF) and horizontal flow (HF) CWs. A hybrid CW, a combination of various wetland systems, was also introduced for the treatment of wastewater (Wu et al. 2015). For the purpose of this paper, only a subsurface flow constructed wetland and especially the horizontal subsurface flow constructed wetland planted by Phragmites australis is considered.

Microorganisms play a vital role in degradation of multiple pollutants in CWs. It has been recognized that the removal of most pollutants in CWs is due primarily to microbial activity (Meng et al. 2014). Removal of a particular pollutant is typically associated with a specific microbial functional group, therefore the employment of design and operational methodologies that enhance the activity of that group will better optimize performance (Faulwetter et al. 2009). 
1 It has long been renowned that many naturally occurring rhizosphere bacteria and fungi may

2 offer a viable substitute for the use of chemicals and are antagonistic towards crop pathogens.

3 Thus, Plant growth promoting rhizobacteria (PGPR) has been shown beneficial to plant

4 growth and health by emancipating their activity on nitrogen fixation, the production of

5 phytohormones and antifungal compounds, and induced systemic resistance (Sindhu, $6 \quad$ Rakshiya, and Sahu 2009).

7 Based on the importance of rhizosphere competence or root colonization in beneficial plant8 microbe interactions (Ben Saad et al. 2016), the main goal of the present study was to enhance 9 the inactivation of pathogenic bacteria rates in horizontal subsurface flow constructed wetland system planted by Phragmites australis using antagonistic bacteria. This work aimed to demonstrate the beneficial application of biotechnology to confer higher rhizosphere competence in the removal of pathogenic bacteria; S. typhi ATCC 560 by environment friendly biological approaches.

\section{Methods}

\section{Sampling and isolation of bacterial strains from different environments}

Bacterial strains were isolated from different ecological niches: wastewater, soil, Phragmites australis roots and sheets from the Technical Demonstration Center (TDC) that treats sewage from the university home located at the Agronomic Institute of Tunis (INAT). Rhizosphere samples were collected from each wetland at the entrance, middle, and exit at a depth of approximately $30 \mathrm{~cm}$ under the gravel surface. All samples were processed in the laboratory. To isolate bacteria from the rhizosphere, the roots were initially separated from the rhizomes, and then small pieces of roots were immersed in sterile saline solution $(0.85 \mathrm{~g} / \mathrm{L} \mathrm{NaCl})$ and vortexes $15 \mathrm{~min}$ in order to release the bacteria attached to roots into the solution. 
1 The same protocol was followed to isolate bacteria from the sets of reeds. Concerning the

2

\section{Identification of the strain and detection of siderophores production}

The identification of selected bacteria was based on the phenotypical aspect of colonies, the microscopic examination standard microbiological and biochemical tests. Siderophore was detected by the method of Jalal and Vander Helm (1990) using a spectrophotometric assay where a peak at $495 \mathrm{~nm}$ on the addition of $2 \%$ aqueous solution of $\mathrm{FeCl}_{3}$ to $1 \mathrm{~mL}$ of supernatant indicated the presence of siderophores.

\section{Antagonism test between isolated bacterial strains and against pathogenic bacteria} S. typhi ATCC 560

Antagonism test had been performed between isolated bacterial to avoid negative interaction between them after their bioinoculation. The Petri dish surface was seeded by an indicative strain and then the blank discs deposited on the culture medium had been drenched with $50 \mu \mathrm{L}$ of filtered supernatant of a putative antagonist strain, collected after centrifugation at 4000 r.p.m for $15 \mathrm{~min}$. The diffusion of the antimicrobial agents was enhanced by incubation at $37^{\circ} \mathrm{C}$ for $24 \mathrm{hr}$. Antagonist activity was revealed by the appearance of inhibition zone around the discs.

\section{Study of motility of isolated bacteria and biofilm production.}

The different types of mobility (swimming, swarming and twitching) were determined by the method of Reimmann et al. (2002). The biofilm production of bacterial isolates was detected by two methods: the first described by Freeman and al. (1989), consisted of plating the test strains on solid medium contained brain heart infusion broth $37 \mathrm{~g} / \mathrm{L}$, sucrose $50 \mathrm{~g} / \mathrm{L}$, agar 10 $\mathrm{g} / \mathrm{L}$ and Congo Red indicator $8 \mathrm{~g} / \mathrm{L}$ (Sujatha N. 2013). After incubation at $30^{\circ} \mathrm{C}$ for $24 \mathrm{hr}$, 
1 black colonies indicate biofilm production. After this qualitative study, we proceeded in a

2 quantitative study describes by O'Toole (1998). This method uses the dye crystal violet (CV).

3 biofilm production was estimated by spectrophotometric measurement of the OD $600 \mathrm{~nm}$.

4

5

\section{Molecular identification of the selected strain}

Bacterial DNA was extracted and purified using the v-DNA reagent (GenIUL) according to the manufacturer's instructions. The concentration of the extracted DNA was measured using a spectrophotometer at $260 \mathrm{~nm}$. DNA purity was estimated from the A260/A280 ratio. The complete 16S rRNA gene was amplified using bacterial primers 27F (5'-TAC GGY TAC CTT GTT AYG ACT T-3') and 1492Rmod (5'-AGR GTT TGA TCM TGG CTC AG-3'). Each PCR reaction with a final volume of $25 \mu$ contained: $2 \mu 1$ of template DNA, $0.5 \mu 1$ of each deoxynucleoside triphosphate at a concentration of $10 \mu \mathrm{M}, 0.75 \mu \mathrm{l}$ of $\mathrm{MgCl} 21.5 \mathrm{mM}$, $0.5 \mu \mathrm{l}$ of each primer at a concentration of $10 \mu \mathrm{M}, 0.125 \mu \mathrm{l}$ of Taq DNA polymerase (Invitrogen), $2.5 \mu$ l of PCR buffer supplied by the manufacturer (Invitrogen, Paisley, UK) and Milli-Q water up to the final volume. Reactions were carried out in a Biorad thermocycler using the following program: initial denaturation at $94^{\circ} \mathrm{C}$ for $5 \mathrm{~min}$, followed by 30 cycles of $1 \mathrm{~min}$ at $94^{\circ} \mathrm{C}, 1 \mathrm{~min}$ at $55^{\circ} \mathrm{C}$ and $2 \mathrm{~min}$ at $72^{\circ} \mathrm{C}$, and a final extension step of $10 \mathrm{~min}$ at $72^{\circ} \mathrm{C}$. PCR products were verified and quantified by agarose gel electrophoresis with standard low DNA mass ladder (Invitrogen). Purification and One Shot Sanger sequencing of 16S rRNA gene products was performed by Genoscreen (Lille, France) with primers 27F and 1492Rmod.

\section{Conception and construction of the pilot-scale systems}

The experimental system designed for the bio-inoculation, included two small parallel identical horizontal subsurface flow constructed wetlands. Both basins were filled with gravel and planted with reed. The first one served as a control and the second served for the different 
1 bio-assays. The size of each constructed wetland bed was $0.3 \times 0.44 \times 0.28$. The treatment

2 area was packed with $8-12 \mathrm{~mm}$ diameter pea gravel while bigger and larger gravel of 30-

$380 \mathrm{~mm}$ diameter was used at the inlet and outlet areas in order to prevent clogging of the filter

4 media. The relative porosity has been calculated in $0.26(\mathrm{n}=\mathrm{Vv} / \mathrm{Vt}$ where $\mathrm{Vv}$ is the void

5 volume and Vt is the total volume (Meng et al. 2014)). The pilote constructed wetlands had

6 bottom slope of $1 \%$ to facilate the flow of water by gravity. The plants were allowed to grow

7 and multiply over three months. There was a peridioc application of wastewater to serve as a

8 source of nutrients for the plants. The main characteristics of the experimental system are as

9 follows: Surface area: $13.2 \mathrm{dm}^{2}$, Hydraulic Residence Time HRT (theoretical): 0.385 , Gravel 10 depth: $2 \mathrm{dm}$, Average starting reed heights: $57 \mathrm{~cm}$. The figures 1 and 2 show the conception of 11 horizontal subsurface flow constructed wetland systems adopted in this study.

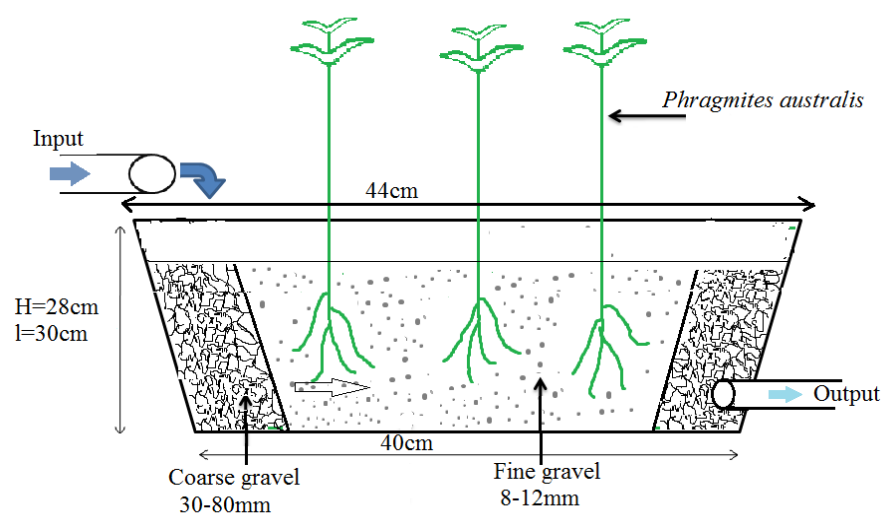

Figure1. The representative figure of the pilot-scale of subsurface flow constructed wetland

\section{Monitoring of bacteria removal}

To optimize the experience, the kinetic growth of the selected strain was determined using a spectrophotometer to estimate absorbance of cell suspensions $\left(\mathrm{DO}_{600}\right)$. Series tests were conducted to determine the lag time that made the selected bacteria to adapt to new conditions.

The experience in situ was done as follows: Phase I start from the sowing of interest bacteria into the rizosphere environment. The main events are activation of the antagonist inoculum 
1 and establishment of an antagonist population in the plant rizosphere. Phase II is the process

2 of the introduced antagonist and native root-associated microbes to establish a population

3 density and persist in the rhizoplane, rhizosphere or inside the root.

4 Therefore, the antagonist bacterium was inoculated into the rhizosphere of the pilot-scale (F).

5 After an adaptation period (depends on growth kinetic parameters), a contaminated effluent

6 by $10^{4} \mathrm{UFC} / \mathrm{ml}$ of an indicator bacteria; S. typhi ATCC 560 was added for both pilot- scales (F 7 and $\mathrm{T})$.

8 Based on growth kinetic parameters of interest bacteria $\left(\mathrm{PFH}_{1}\right)$, sequential bio-injections were performed in pilot scale $(\mathrm{F})$ to test of the spatio-temporal dynamics and microbial ecological processes of root colonization by an antagonist and to explore the impact of accumulation effect of sequential bioinoculation of antagonist bacteria to promote inhibition of pathogenic bacteria.

The monitoring of pathogenic bacteria removal after bioinoculation was determined by culture on selective medium (SS: Selmonella Shigella agar).

\section{Results and discussion}

\section{Isolation and Screening of bacterial strains}

After sampling, isolation and purification stages, 19 bacterial strains were isolated from different ecological niches from the Technical Demonstration Center (TDC) that treats sewage from university home located at the Agronomic Institute of Tunis (INAT). The isolats strains were selected and screened for general functional properties of plant promoting rhizobacteria; namely, siderophore production and antagonist activity against pathogenic bacteria in addition of the bacterial motility (swimming, swarming and twitching motilities) and biofilm production. 
1 Bacterial biofilm formation is important for root colonization. Indeed, root-associated bacteria

2 have been studied extensively, and many of these promote the growth of host plants or are

3 used as biocontrol agents (Dekkers et al. 1998). The plant-growth-promoting bacteria have

4 been reported to discontinuously colonize the root surface, developing as small biofilms along

5 epidermal fissures.

6 Among the isolates, we were screened $\mathrm{PFH}_{1}$ strain to apply as an interest to be inoculated into

7 the rizospheric zone to enhance the reduction of pathogenic bacteria. Indeed, the antagonism

\section{Molecular identification of the selected strain}

The 16S rRNA gene sequences of the selected bacteria were determined. The sequence analysis revealed that this bacteria has $99 \%$ of similarity with Enterobacter cloaceae.

Enterobacter cloacae are a gram-negative Proteobacterium belonging to the Enterobacteriaceae family. Within this family, Enterobacter is most closely related to, and is grouped in a sub-clade with, Klebsiella. The E. cloacae species comprises an extremely diverse group of bacteria that has been found in diverse environments, ranging from plants to soil to humans (Liu et al., 2013).

Enterobacter species have been reported as both plant pathogens and human opportunistic pathogens (Nishijima et al., 2007), and also as important engineering and plant growthpromoting bacteria (Nie et al., 2002). Some Enterobacter strains may play important roles in plant-microbe interactions and hence in biocontrol mechanisms. In this sense, we are used the 
1 selected bacteria to control the pathogenic density and its application to improve the water

2 treatment by constructed wetland.

3

4 To optimize the experience and before inoculation into the rhizosphere, the kinetic growth of

$5 \mathrm{PFH}_{1}$ strain was investigated in saline water and autoclaved wastewater at room temperature

6 in order to determine the specific growth characteristics of $\mathrm{PFH}_{1}$ namely the lag time, $\left(\Lambda_{\mathrm{t}}\right)$ the

8

\section{Application bioinoculation of selected bacteria.}

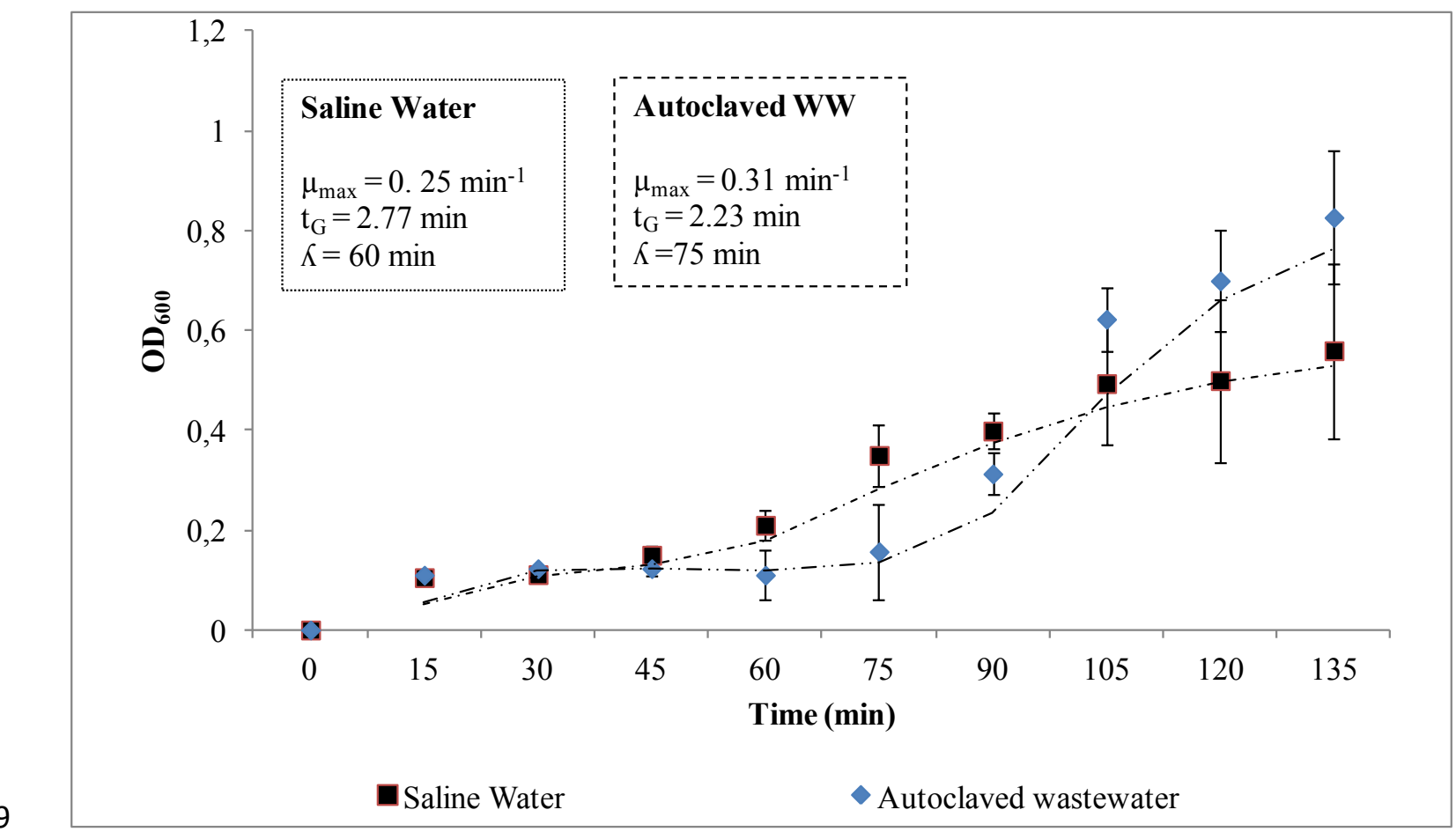

Figure 2. Kinetics growth of $\mathrm{PFH}_{1}$ in different growth temperature conditions.
Data are averages of three experiments

\subsection{Removal of pathogenic bacteria with single bioinoculation}
The figure 3 shows the kinetic of bacteria removal with an initial concentration of indictor bacteria (S. typhi) equal to $10^{6} \mathrm{UFC} / \mathrm{ml}$ in presence of $\mathrm{PFH}_{1}$. 
1 After a retention time equal to 3 hours, we were noticed a reduction in the number of pathogenic

2 bacteria (S. typhi) in both filters: inoculated and non inoculated one (F and T pilot-scale filters).

3 The kinetics of $S$. typhi inactivation turns in perfect agreement with the model of Chick-

$4 \quad$ Watson $(\mathrm{CW})$ model with modification:

5

6

$$
N / N_{o}=A \exp \left(-k^{n} \cdot t\right)
$$

With ; $N / N_{0}$ : is the reduction in the indicator bacterial concentration, $N$ : Number of viable cultivable bacteria at time $t ; N_{0}$ : Number of viable and cultivable bacteria at time $t_{0} ; k$ : Coefficient of inactivation; $A$ : The bacterial reduction rate; $n$ : threshold inactivation or threshold events suffered by the bacterium after inactivation series, $n=1$ for first degree model.

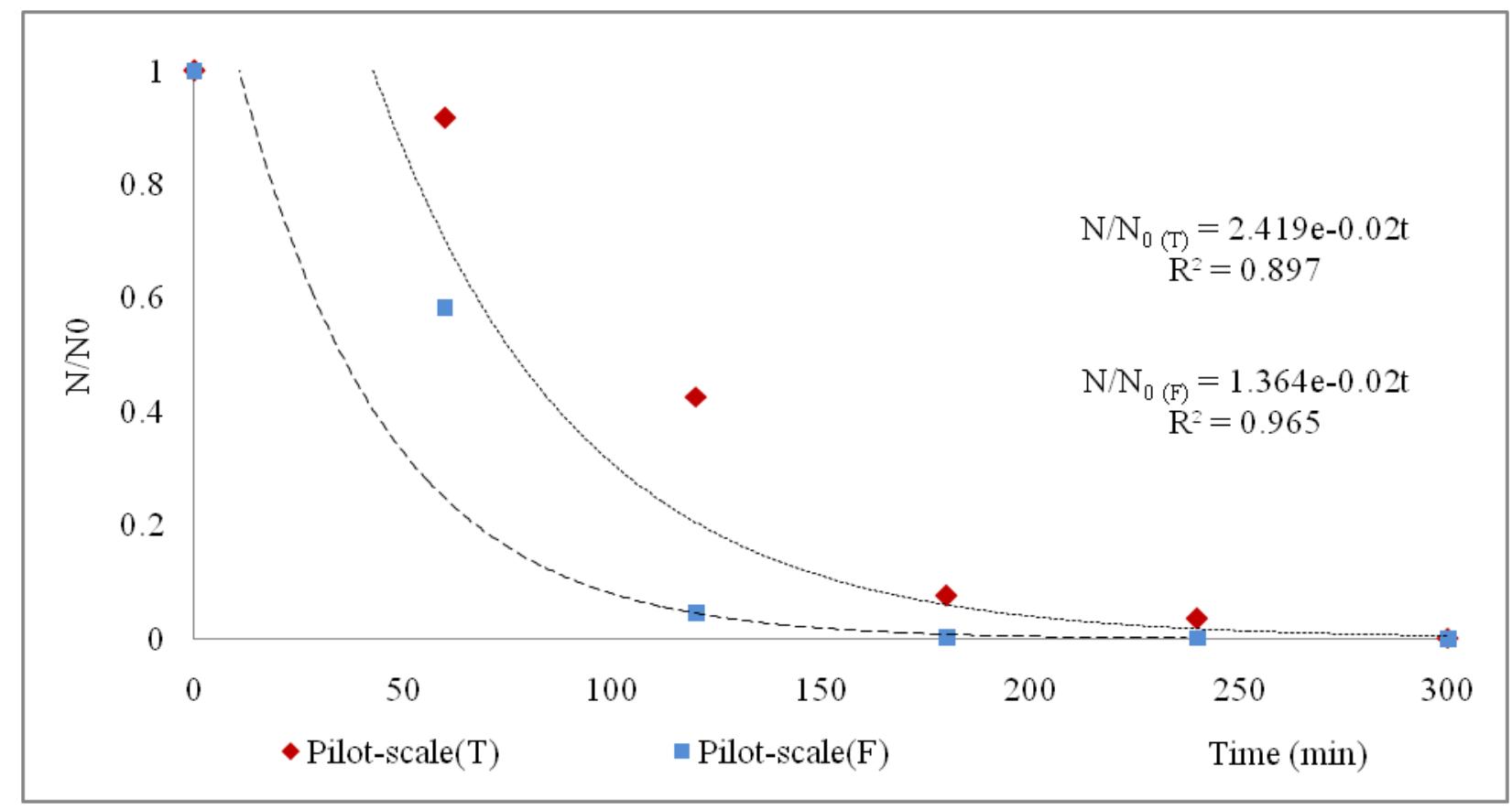

Figure 3. The kinetic of pathogen bacteria removal in the two filters (T) and (F) with single bioinoculation.

Data are averages of three experiments.

By analysis of bacterial inactivation curves, we can note an increase in bacterial reduction over time in the both pilot scales filters with a difference in the bacteria inhibition rate. 
1 The injection of selected bacteria into the rhizosphere of Phragmites australis improves the

2 kinetics of $S$. typhi inactivation by approximately $1 \mathrm{U}-\log _{10}\left(\mathrm{~N} / \mathrm{N}_{0}\right)$ compared to the control

3 mini- filter $(\mathrm{T})$.

4 The enhancement of $0.8 \mathrm{U}-\log _{10}$ of bacteria inactivation in inoculated filter (F) during a short

5 retention time $(5 \mathrm{hrs})$ is probably related to a good colonization ability of the rhizosphere and to

6 the antagonist activity of the selected inoculated strain.

7 Several studies demonstrate the effectiveness of macrophytes systems in the elimination of 8 pathogenic bacteria strain (Hill et Sobsey 2001). Other study showed that the reduction of the 9 pathogenic bacterium $S$. typhi is equal to $2.3 \mathrm{U}-\log _{10}(\mathrm{~N} / \mathrm{N} 0)$ for treatment of primary sewage in small communities and rural areas using gravel during a retention time of 23 to 52 hours (Hench et al. 2003).

12 The exploitation of the results of bacterial reduction by modified kinetic models CW has allowed us to determine different kinetics parameters. The most important values are: the coefficient of inactivation $(k)$ and the bacterial reduction rate in the contact with autochtone rizobacterium with and without bioinoculation $(A)$.

The analysis of kinetic parameters shows an increase of the inactivation coefficient $(k)$ that represents the slope of inactivation curve; determined for inoculated pilot-scale $(F)$ with an antagonistic bacteria $\left(\mathrm{PFH}_{1}\right)$. The increase of this coefficient confirms the effectiveness of inoculated bacteria to strengthen the rhizospheric effect and increase the reduction of pathogenic bacteria. .

For the bacterial reduction rate $(A)$, this parameter shows a small decrease for inoculated minifilter compared to the control mini-filter $(\mathrm{T})$. This parameter revel the inactivation of target bacteria at the first contact with autochtone rhizospheric biomass with and without Bio-helper (bio-inoculation). The stabilization of this parameter indicated directly the need of acclimation 
1 time for the inoculated bacteria to the in situ environment. Therefore, the first inactivation effect

2 was govern by autochthone biomass by various interactions such as antibiosis, biological

3 antagonism, the competition for nutrients and parasitism (Di Francesco, Martini, and Mari 2016).

4 By a single inoculation of antagonistic bacteria, we can increase pathogenic bacteria removal

5 by $1.6 \mathrm{U}-\log _{10}$ of initial indicator bacteria. This result affirms well the use of bioinoculation

6 for biocontrol.

7 The enhancement of the rhizobacterium potential in mini-filter planted by Phragmites

8 australis is strongly related to antagonist bacteria growth parameters, namely, the lag time $\left(\kappa_{\mathrm{t}}\right)$

9 the maximum specific growth rate $\left(\mu_{\max }\right)$, the bacterium generation time $\left(t_{G}\right)$.

In the control minifilter (T), the inhibition of pathogenic bacteria (S.typhi) is carried out by the autochthon bacterial colonization of the rhizoplane.

12 The bacterial inactivation kinetic is in perfect agreement with the first order model of ChickWatson (Equation1).

However, in the mini-filter $(\mathrm{F})$, after bioinoculation of interested bacteria $\left(\mathrm{PFH}_{1}\right)$, we cannot apply the first order model of Chick-Watson to report the effect of bioinoculation on indicator bacteria inactivation. Indeed, in the inoculated pilot-scale, we must consider several parameters. The most important are: the growth parameters of inoculated bacteria (the lag time, $\left(\Lambda_{\mathrm{t}}\right)$ the maximum specific growth rate $\left(\mu_{\max }\right)$, the bacterium generation time $\left(\mathrm{t}_{\mathrm{G}}\right)$, the adaptable time, etc. For example the optimal growth rate of inoculate bacteria $\left(\mu_{\mathrm{opt}}\right)$ is determined where all environmental conditions are optimal such as temperature $\left(t_{\mathrm{opt}}\right), \mathrm{pH}(\mathrm{pH}$ opt $)$, the water activity 21 (aw $\left.{ }_{\text {opt }}\right)$, etc. The combined effect of several environmental factors is then determined by multiplying the respective gamma factors. The Gamma concept was introduced by Zwietering et al. (1992) 
1 and is based on two principles: (i) all measurable factors, that influence the growth rate $(\mu)$,

2 are independent and occur multiplicatively:

$$
\mu=f(\theta) \times f(\mathrm{pH}) \times f(\mathrm{aw}) \times \ldots f(\text { others })
$$

4 (ii) The effect of each environmental factor on the growth rate can be represented by a 5 fraction of the maximum growth rate:

6

7

8 9

10

$$
\begin{aligned}
& \gamma=\boldsymbol{\mu} / \mu_{\text {opt }}(\text { Comprise between } 0 \text { and } 1) \\
& \boldsymbol{\mu}_{\max }=\boldsymbol{\mu}_{\text {opt }} \gamma(\boldsymbol{\theta}) \gamma(\mathbf{p H}) \gamma(\mathbf{a w}) \ldots \gamma(\text { others })
\end{aligned}
$$

Where $\gamma$ : represents a function taking into account the factor influencing $\mu_{\mathrm{opt}} ; \boldsymbol{\theta}$ : temperature

In the inoculated mini-filter $(\mathrm{F})$ we cannot overlook the contribution of autochthon rizobacterium in pathogen bacteria removal. Indeed, the antagonist activity of inoculated bacteria set up after a lag time $\left(\Lambda_{\mathrm{t}}\right)$ :

$$
\begin{aligned}
& \text { If } \mathrm{t}<\boldsymbol{\Lambda}_{\mathrm{t}}+\alpha ; N / N_{o}=A_{T} \exp (-k . t) \\
& \text { If } \mathrm{t} \geq \boldsymbol{\Lambda}_{\mathrm{t}}+\alpha ; N / N_{o}=A^{\prime} \exp \left(-k^{\prime} \cdot t\right)
\end{aligned}
$$

In the mini-filter $(\mathrm{F})$, we can model the inactivation kinetics of indicator bacteria as following:

$$
N / N_{o}=A \times\left(1+\mu_{\max }\right)_{\alpha} \exp \left[\left(-k \times\left(1+\mu_{\max }\right)^{n+m}\right] t\right.
$$


1 Where, $N / N_{0}$ : is the reduction in the indicator bacterial concentration, $N_{t}$ : Number of viable

2 cultivable bacteria at time $t ; N_{0}$ : Number of viable and cultivable bacteria at time $t_{0} ; k$ :

3 Coefficient of inactivation; $A$ : The bacterial reduction rate; $k^{\prime}$ : coefficient of bacteria inactivation

4 related by the presence of injected bacteria; $A^{\prime}$ : The bacterial removal rate related by the

5 presence of injected bacteria, $m$ : threshold inactivation or threshold events undergo by the

6 bacterium after bioinoculation and $\alpha$ : A acclimation time of inoculated bacteria.

\section{2.2. Removes bacteria with sequential bioinoculation}

8 To strengthen the rhizocompetence in pathogen removal bacteria, sequential injections of the

9 selected bacteria were performed at time 0,60,120 $\mathrm{min}$ and $180 \mathrm{~min}$. The choice of the 10 injection time was based on the bacterium lag time that equal to $60 \mathrm{~min}$ (Figure 4).

11

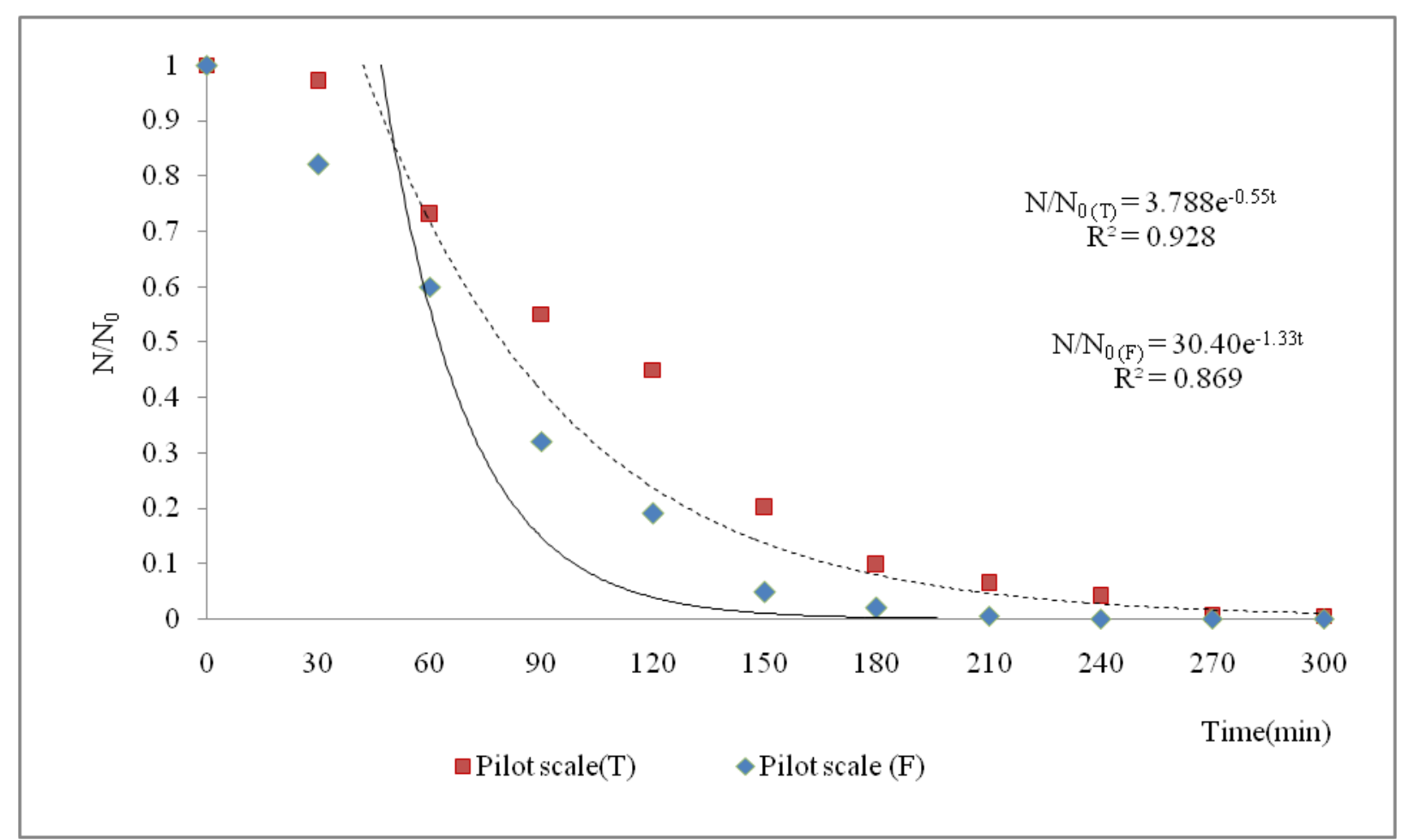

Figure 4. The kinetic of pathogen bacteria removal in mini-filter (F) with sequential bioinoculation of antagonistic bacteria. 
1 By a series of multi-bioinoculation, we can see the enhancement of pathogen bacteria

2 reduction compared to the inhibition rate in control pilot-scale $(\mathrm{T})$ by $2 \mathrm{U}-\log _{10}\left(\mathrm{~N} / \mathrm{N}_{0}\right)$.

3 The accumulative effect of sequential bio-injection and the keeping of the exponential growth

4 phase of interest bacteria (based on the growth curve of $\mathrm{PFH}_{1}$ strain) allowed us to increase

5 the coefficient of indicator bacteria inactivation $(k)$ to $1.33 \mathrm{~min}^{-1}$ determined after three bio-

6 injection in mini-filter $(\mathrm{F})$ versus a value of $k$ equal to $0.35 \mathrm{~min}^{-1}$ determined in the control

7 mini-filter (T) without bio-injection.

8 We can note the increase of inactivation rate $(A)$ determined for inoculated pilot-scale (F)

9 compared to control scale.

The difference in kinetic parameter $(k$ and $A$ ) determined for both mini-filter $\mathrm{T}$ and $\mathrm{F}$ is proportional of growth bacteria factors $\left(\kappa_{t}\right)$ the maximum specific growth rate $\left(\mu_{\max }\right)$, the bacterium generation time $\left.\left(t_{G}\right)\right)$.

The enhancement of pathogen inactivation rate is positively correlated with the growth bioinoculum factors $\left(A^{\prime}\right.$ and $\left.k^{\prime}\right)$ and the number of injection.

We can modulate this result as following:

$$
N / N_{o}=\left[A \times\left(1+\mu_{\max }\right)_{\alpha} \exp \left[\left(-k \times\left(1+\mu_{\max }{ }^{n+m}\right] t\right]^{\mathrm{b}}\right.\right.
$$

With, $b$ : the number of inoculation.

To resume, after the accumulation effect of three sequential bio-injections into a rizosphere environment of Phragmites australis, the rizocompetence in bacterial removal was increased by $k^{\prime}\left(1.33 \mathrm{~min}^{-1}\right)$ and $A^{\prime}(30.4)$ relative to the antagonist activity of interest bacteria with a reduction in contact time. The bioinoculation of antagonist showed positive results for most of the evaluated traits single and multisequential injections), demonstrating the great potential of this practice use in order to increase the quality of sanitary. The results of the present study reaffirm the possibility of 
1 developing a commercial bioinoculant to be applied in biological water treatment process to

2 improve the treated water quality.

3

4 CONCLUSION

5 From the present research, we can conclude that application of bioinoculation has a potential

6 to enhance the pathogenic bacteria removal process. Indeed, the preliminary results show the

7 beneficial effect of the bioinoculated strain $\left(\mathrm{PFH}_{1}\right)$ in the rhizosphere to increase remarkably

8 the efficiency of the water treatment system for the reduction of pathogenic bacteria with a

9 reduction in contact time.

10 This study has contributed with an eco-friendly strategy to improve water treatment process

11 by constructed wetland, and highlighted the fact that better yields can be obtained thought bio-inoculation.

As a perspective of this study, the application of this strategy in field conditions with multiinoculation of antagonists substances protected by natural polymers to inactivate pathogenic bacteria in treated water without chemical addition, extension in the retention time or addition of a complement water treatment stages.

\section{Acknowledgment}

This work is supported by CERTE contract programs funded by the Ministry of Higher 19 Education and Scientific Research of Tunisia.

\section{References}

Ben Saad M, Ben Said M, Bousselmi L, and Ghrabi A (2016) Application of Bioinoculation to Enhance Rhizocompetence of Horizontal Subsurface Flow Constructed Wetland System, Desal and Wat Treat 57 (46): 22133-39. doi:10.1080/19443994.2016.1141713.

Dekkers, L C, C C Phoelich, L van der Fits, and B J Lugtenberg. 1998. "A Site-Specific Recombinase 
Proceedings of the National Academy of Sciences of the United States of America 95 (12): 705156. doi:10.1073/pnas.95.12.7051.

Faulwetter, Jennifer L., Vincent Gagnon, Carina Sundberg, Florent Chazarenc, Mark D. Burr, Jacques Brisson, Anne K. Camper, and Otto R. Stein. 2009. "Microbial Processes Influencing Performance of Treatment Wetlands: A Review." Ecological Engineering 35 (6): 987-1004. doi:10.1016/j.ecoleng.2008.12.030.

Francesco, A. Di, C. Martini, and M. Mari. 2016. "Biological Control of Postharvest Diseases by Microbial Antagonists: How Many Mechanisms of Action?" European Journal of Plant Pathology 145 (4). European Journal of Plant Pathology: 711-17. doi:10.1007/s10658-016-08670 .

Ghrabi, Ahmed, Latifa Bousselmi, Fabio Masi, and Martin Regelsberger. 2011. "Constructed Wetland as a Low Cost and Sustainable Solution for Wastewater Treatment Adapted to Rural Settlements: The Chorfech Wastewater Treatment Pilot Plant." Water Science and Technology 63 (12): 300612. doi:10.2166/wst.2011.563.

Hench, K R, G K Bissonnette, A J Sexstone, J G Coleman, K Garbutt, and J G Skousen. 2003. "Fate of Physical, Chemical, and Microbial Contaminants in Domestic Wastewater Following Treatment by Small Constructed Wetlands." Water Res 37 (4): 921-27. doi:S00431354(02)00377-9 [pii].

Hill, V.R. R., and M.D. D. Sobsey. 2001. "Removal of Salmonella and Microbial Indicators in Constructed Wetlands Treating Swine Wastewater." In Water Science and Technology, 44:21522.

Liu, Ranbin, Yaqian Zhao, Liam Doherty, Yuansheng Hu, and Xiaodi Hao. 2015. "A Review of Incorporation of Constructed Wetland with Other Treatment Processes." Chemical Engineering Journal. doi:10.1016/j.cej.2015.05.023.

Liu, Wing-Yee, Chi-Fat Wong, Karl Ming-Kar Chung, Jing-Wei Jiang, and Frederick Chi-Ching Leung. 2013. "Comparative Genome Analysis of Enterobacter Cloacae." PLoS ONE 8 (9): e74487. doi:10.1371/journal.pone.0074487.

Meng, Panpan, Haiyan Pei, Wenrong Hu, Yuanyuan Shao, and Zheng Li. 2014. "How to Increase Microbial Degradation in Constructed Wetlands: Influencing Factors and Improvement Measures." Bioresource Technology 157. Elsevier Ltd: 316-26. doi:10.1016/j.biortech.2014.01.095.

Nie L, Shah S, Rashid A, Burd GI, Dixon DG, Glick BR (2002) Phytoremedation of arsenate contaminated soil by transgenic canola and the plant growth-promoting bacterium Enterobacter cloacae CAL2. Plant Physiol Biochem 40, 355-361

Shen, Zhiqiang, Yuexi Zhou, Jia Liu, Yu Xiao, Rong Cao, and Fuping Wu. 2015. "Enhanced Removal of Nitrate Using starch/PCL Blends as Solid Carbon Source in a Constructed Wetland." Bioresource Technology 175. Elsevier Ltd: 239-44. doi:10.1016/j.biortech.2014.10.006.

Sindhu, Satyavir S., Yuvraj S. Rakshiya, and Govind Sahu. 2009. "Biological Control of Soilborne Plant Pathogens." Pest Technology 3: 10-21. doi:10.1017/S0889189300002253.

Sujatha N., and K. Ammani. 2013. "Siderophore Production By the Isolates of Fluorescent Pseudomonads." International Journal of Current Research and Review 5 (20): 1-7. 
http://www.scopemed.org/?mno=47599.

Tee, Pei Fang, Mohammad Omar Abdullah, Ivy Ai Wei Tan, Nur Khairunnisa Abdul Rashid, Mohamed Afizal Mohamed Amin, Cirilo Nolasco-Hipolito, and Kopli Bujang. 2016. "Review on Hybrid Energy Systems for Wastewater Treatment and Bio-Energy Production." Renewable and Sustainable Energy Reviews 54: 235-46. doi:10.1016/j.rser.2015.10.011.

Vymazal, Jan. 2014. "Constructed Wetlands for Treatment of Industrial Wastewaters: A Review." Ecological Engineering 73. Elsevier B.V.: 724-51. doi:10.1016/j.ecoleng.2014.09.034.

Wang, Qian, Huijun Xie, Huu Hao Ngo, Wenshan Guo, Jian Zhang, Cui Liu, Shuang Liang, Zhen Hu, Zhongchen Yang, and Congcong Zhao. 2015. "Microbial Abundance and Community in Subsurface Flow Constructed Wetland Microcosms: Role of Plant Presence." Environmental Science and Pollution Research. doi:10.1007/s11356-015-4286-0.

Wang, Xiaoou, Yimei Tian, Xinhua Zhao, Sen Peng, Qing Wu, and Lijian Yan. 2015. "Effects of Aeration Position on Organics, Nitrogen and Phosphorus Removal in Combined Oxidation PondConstructed Wetland Systems." Bioresource Technology 198. Elsevier Ltd: 7-15. doi:10.1016/j.biortech.2015.08.150.

Wu, Haiming, Jian Zhang, Huu Hao, Wenshan Guo, Zhen Hu, Shuang Liang, Jinlin Fan, et al. 2015. "A Review on the Sustainability of Constructed Wetlands for Wastewater Treatment: Design and Operation." Bioresource Technology 175. Elsevier Ltd: 594-601. doi:10.1016/j.biortech.2014.10.068.

Wu, Shubiao, Scott Wallace, Hans Brix, Peter Kuschk, Wesley Kipkemoi, Fabio Masi, Renjie Dong, Wesley Kipkemoi Kirui, Fabio Masi, and Renjie Dong. 2015. "Treatment of Industrial Effluents in Constructed Wetlands: Challenges, Operational Strategies and Overall Performance." Environmental Pollution 201. Elsevier Ltd: 107-20. doi:10.1016/j.envpol.2015.03.006.

Zaytsev, Igor, Ülo“"Mander, Krista Lõhmus, and Kaspar Nurk. 2011. "Enhanced Denitrification in a Bioaugmented Horizontal Subsurface Flow Filter." Ecological Engineering 37 (7): 1050-57. doi:10.1016/j.ecoleng.2010.10.007.

Zhang, Dong Qing, K. B S N Jinadasa, Richard M. Gersberg, Yu Liu, Wun Jern Ng, and Soon Keat Tan. 2014. "Application of Constructed Wetlands for Wastewater Treatment in Developing Countries - A Review of Recent Developments (2000-2013)." Journal of Environmental Management 141. Elsevier Ltd: 116-31. doi:10.1016/j.jenvman.2014.03.015. 